\title{
El ADN cooperativo y solidario de la Universidad Cooperativa de Colombia: las raíces de su identidad institucional
}

\author{
Cooperative and Supportive DNA of the Universidad \\ Cooperativa de Colombia: Roots of Institutional Identity
}

Milcíades Vizcaíno-G. $\otimes^{1}$

${ }^{\top}$ Universidad Cooperativa de Colombia, Villavicencio, Colombia

\begin{tabular}{|c|c|c|}
\hline Recibido: 6 de enero del 2017 & Aprobado: 18 de julio del 2017 & Disponible en línea: 14 de enero del 2018 \\
\hline
\end{tabular}

\section{Resumen}

Propósito: la pregunta central que se propone responder este artículo es: ¿Qué identidad se ha forjado la Universidad Cooperativa de Colombia y qué continuidades y discontinuidades presenta a lo largo de su funcionamiento? Dado que la universidad — como todas las de su género— es una organización compleja que presenta múltiples dimensiones derivadas de su misión, no es posible tenerlas todas en cuenta.

Descripción: esta presentación sucinta se concentra solo en la identidad institucional. La trayectoria histórica está atravesada por esta.

Punto de vista: interesa dilucidar si la historia de la Universidad Cooperativa de Colombia ha sido un testimonio de fidelidad a sus raíces, origen de su identidad, y si sus lemas de "Una universidad, todo un país", y "Navegando juntos", expresan su vocación y destino, que nacen de la intencionalidad de sus fundadores.

Conclusiones: las huellas de la identidad institucional se exploran con un marco analítico útil que permite revisar históricamente la conformación y el papel de Indesco, el Instituto de Economía Social y Cooperativismo, para luego constituirse en Universidad Indesco y posteriormente en Universidad.

Palabras clave: identidad institucional, Indesco, trayectoria, Universidad Cooperativa de Colombia. 


\title{
Cooperative and Supportive DNA of the Universidad Cooperativa de Colombia: Roots of Institutional Identity
}

\begin{abstract}
Purpose: The central question that this article proposes to answer is what identity has the Universidad Cooperativa de Colombia forged and what continuities and discontinuities does it present throughout its operation? Since the University, like all of its kind, is a complex organization that has multiple dimensions derived from its mission, it is not possible to take them all into account.

Description: This succinct presentation focuses only on institutional identity, which traverses the University's historical trajectory.

Point of view: It is interesting to clarify if the history of the Universidad Cooperativa de Colombia has been a testimony of fidelity to its roots, origin of its identity, and if its mottos of "A university, a whole country" and "Sailing together", express its vocation and destiny, born of the intentionality of its founders.

Conclusions: Traces of institutional identity are explored with a useful analytical framework to historically review the conformation and role of Indesco, the Institute of Social Economy and Cooperativism, that later became Indesco University and later on, a University.

Keywords: institutional identity, Indesco, trajectory, Universidad Cooperativa de Colombia.
\end{abstract}

\section{O DNA cooperativo e solidário da Universidad Cooperativa de Colombia: raízes de identidade institucional}

\section{Resumo}

Propósito: a pergunta central que visa responder este artigo é: que identidade tem forjado a Universidad Cooperativa de Colombia e que continuidades e descontinuidades apresenta ao longo do seu funcionamento? A universidade é uma organização complexa que apresenta múltiplas dimensões derivadas da sua missão, como todas as instituições semelhantes; assim, não é possível ter todas essas dimensões em conta.

Descrição: esta apresentação sucinta concentra-se somente na identidade institucional. A trajetória histórica está atravessada por ela.

Ponto de vista: interessa esclarecer se a história da Universidad Cooperativa de Colombia foi uma prova de fidelidade às suas raízes, a origem da sua identidade, e se os seus lemas de "Uma universidade, todo um país" e "Navegando juntos" expressam a sua vocação e destino, que nascem da intenção dos seus fundadores.

Conclusões: as marcas da identidade institucional são exploradas a partir de um âmbito analítico útil para revisar historicamente a conformação e o papel do Instituto de Economia Social e Cooperativismo (Indesco), que, posteriormente, constituiu-se como Universidad Indesco e que, finalmente, se tornou a Universidad Cooperativa de Colombia.

Palavras-chave: identidade institucional, Indesco, trajetória, Universidad Cooperativa de Colombia. 
La historia no está al lado de nadie. Immanuel Wallerstein (Coolen, 2002)

\section{Introducción}

La Universidad Cooperativa de Colombia tiene una trayectoria de 58 años. Su historia se ha tejido en tres grandes etapas: la primera fue el periodo de fundación y desarrollo inicial de Indesco, entre 1958 y 1970; la segunda, el inicio y la consolidación de la Universidad Indesco, entre 1970 y 1982; y la tercera como Universidad Cooperativa de Colombia, desde 1983 hasta la actualidad.

La pregunta central que se propone responder este artículo es: ¿cuál es la identidad construida para sí por la universidad y qué continuidades y discontinuidades ha presentado a lo largo de su funcionamiento? Dado que la universidad - como todas las de su género- es una organización compleja que presenta múltiples dimensiones derivadas de su misión, no todas ellas se tendrán en cuenta. Por ejemplo, los aspectos académicos, sus logros y vicisitudes, su actividad de investigación con sus productos, difusión y uso social, su proyección al medio social y cultural, su posición relativa en el contexto nacional e internacional, con sus indicadores de logro y de gestión, no se consideran como se hace habitualmente en estudios de la educación superior. La razón es que esta presentación sucinta se concentra solo en la identidad institucional. La trayectoria histórica está atravesada por la identidad que construyeron sus fundadores. Así, la pregunta que se deriva es: ¿qué tanto se ha mantenido fiel a los principios del cooperativismo y de la solidaridad junto con la prestación de un servicio público en educación superior, que son sus orientadores permanentes? La identidad está armada con los dos componentes básicos en una interacción creativa que le otorga su especificidad. A partir de este postulado, una inquietud que surge es: ¿la identidad ha conjugado los dos elementos y ha otorgado similar o diferente peso relativo a cada uno de ellos? En suma, interesa dilucidar si su historia ha sido un testimonio de fidelidad a las raíces que han construido su identidad, y si sus lemas de "Una universidad, todo un país" y "Navegando juntos" expresan su vocación y su destino, construido desde la intencionalidad de sus fundadores hasta nuestros días.

Las huellas de la identidad institucional se exploran con un marco analítico que se usa para revisar históricamente la conformación y el papel del Indesco, el Instituto de Economía Social y Cooperativismo, para luego constituirse en Universidad Indesco y, posteriormente, en Universidad. Estos aspectos se exponen en la primera parte. En la segunda se aportan evidencias acerca de la historia que se desenvuelve en vaivenes agenciados por influencias externas y por procesos internos a lo largo de las seis décadas de existencia. En una tercera parte, se sitúa la mirada en el futuro de los procesos internos que, con influencias externas, se advierten a mediados de la segunda década del siglo XXI.

\section{El lente de la identidad institucional}

Hacer visible la identidad institucional es pertinente no solo para la misma universidad, sino también para la herencia cooperativa, para Indesco y la educación superior colombiana. Esta universidad es un caso prototípico en el cual confluyen los principios de la economía social con la función pública de desarrollo de un proyecto de educación superior. El supuesto de partida es que la identidad originaria ha mostrado cambios, precedencias y transformaciones en el trascurso de los años; por tanto, se hace necesaria la aplicación de procedimientos de arqueología y de reconstrucción histórica en una mirada ex post facto y en la perspectiva de un futuro deseable.

Resulta un reto intelectual adentrarse en los factores que contribuyeron a la gestación de la identidad, sus permanencias y modificaciones, sus núcleos de persistencia y sus transformaciones hasta los años recientes, así como su proyección futura. La mirada hacia adentro de la institución -y los ojos puestos en el afuera, en el entornocumplirán la función complementaria de buscar coincidencias, pero también desajustes que se convierten en factores que ayuden a la comprensión de la dinámica histórica. Las instituciones corren el riesgo del "presentismo", lo cual aleja de la vocación original y de avanzar hacia un futuro deseable. En la Universidad Cooperativa de Colombia, han pasado generaciones de directivos, docentes, estudiantes y beneficiarios de las acciones de la universidad. Hacia el futuro, se corre el riesgo de que las nuevas generaciones no comprendan plenamente el significado social, político y cultural que tiene la institución.

Dos lógicas se relacionan entre sí: una es el nivel macroorganizacional que se identifica con la 
totalidad, con la política, los pilares de las estructuras, la filosofía, los principios y los compromisos en su función social; otra es el micronivel en el cual se encuentran las personas que hacen parte de la organización y desempeñan funciones en relación con objetivos preestablecidos. De estas personas surgen afinidades electivas, lealtades, cohesiones, actitudes, representaciones sociales y conductas en la cotidianidad de su vinculación a la organización. No son mundos separados; solo desde el punto de vista analítico se los puede ver de manera independiente (Gomes da Silva, 2010). Es necesario reconstruir los conectores.

La búsqueda procede mediante la resolución de preguntas orientadoras: a) ¿Cuál es la identidad actual de la Universidad Cooperativa de Colombia, qué factores han incidido en su construcción, en qué dirección se ha encaminado, qué permanece y qué innovaciones presenta de su trayectoria histórica?; y b) ¿Cuáles han sido las influencias en la identidad institucional que provienen de los cambios ocurridos en Colombia desde mediados del siglo anterior hasta su inserción en la globalización actual? Los referentes del cooperativismo y de la economía solidaria y las dinámicas de la educación superior constituyen su identidad primaria, la cual se presenta en tres formas:

- Identidad legitimadora. Su función es garantizar la estabilidad en medio de los cambios, especialmente hacia las estructuras de poder externo como son el Estado y la sociedad.

- Identidad de resistencia. Se ocupa de contrarrestar los riesgos y las estigmatizaciones que provienen del entorno y de procesos internos autodestructivos que la propia organización engendra en sus actores.

- Identidad como proyecto. Mira al futuro en el cual encuentran realización sus objetivos estratégicos. Es una construcción, no un descubrimiento; es el blanco del esfuerzo colectivo y no un azar; es un juego de oportunidades dirigidas a un sueño que se hace realidad en la acción (Bauman, 2005).

La identidad otorga unidad en la diversidad de personas y de saberes que caracterizan al espacio universitario (Gutiérrez, 2004). Unidad, en la medida en que todos los actores se encuentran convocados por y para el conocimiento, la ciencia, la formación y el servicio a los estudiantes y a la sociedad. Diversidad, porque tiene en su seno múltiples intereses frente a los saberes, diferentes disciplinas, profesiones y concepciones epistemológicas en los campos del conocimiento. Sin embargo, lo que anuda todos los procesos es el elemento común de la identidad institucional (Cortés, 2011). Resulta pertinente, en consecuencia, evidenciar la fortaleza o debilidad de la identidad institucional con el fin de valorar la direccionalidad de los planes estratégicos en función de su desarrollo y de su presencia en la sociedad.

La identidad se ha convertido, en las décadas recientes, en uno de los conceptos más populares usados en los estudios sobre las organizaciones (Gomes da Silva, 2010). Se acepta, por lo general, que la identidad es una "construcción de sentido" (Solís, 2004, p. 75), en la cual intervienen dialécticamente el individuo y el medio social (Berger y Luckmann, 1998, p. 217), por cuanto "el tema del sentido desde el análisis social es el tema de la identidad" (Solís, 2004, p. 77). Numerosos autores, entre ellos Manuel Castells, otorgan un gran poder al concepto de la identidad entendido como "un proceso de construcción de sentido que atiende a un atributo cultural, al cual se le da prioridad sobre el resto de las fuentes de sentido" (1999, p. 28). En efecto, a sabiendas de que hay otras fuentes de sentido derivados de los campos político o económico, la preferencia por la identidad desplaza a una segunda prioridad a las demás a fin de focalizar el carácter social y cultural. Desde este enfoque se orienta el análisis.

La literatura sociológica y psicológica son ricas en el desarrollo del concepto de fuentes de sentido que inciden en la vida personal o social, pero también en el nivel de las organizaciones. Claro está que no siempre fue así en la historia pasada ya que, por ejemplo, "en un momento histórico de la psicología social en el que la explicación de los procesos psicosociales estaba marcada por enfoques individualistas y anticolectivistas" (Canto y Moral, 2005, p. 67), surgió la teoría de la identidad social. Este fue un quiebre histórico que tuvo la virtud de aliviar las tensiones polares entre individuo y colectividad. Se comprendió que la colectividad se encuentra en los individuos y que ellos son parte integral de la colectividad, de manera que solo desde un ángulo abstracto se las puede diferenciar, pero en la realidad van inexorablemente juntas con variaciones demostradas en sociedades específicas. La explicación es: "Aunque, originariamente, la teoría de la identidad social de Henri Tajfel (1984) se 
dedicara al análisis de las relaciones intergrupales, más recientemente, la teoría de la categorización del yo analiza los procesos grupales, tanto en grupos pequeños como grandes" (Canto y Moral, 2005, p. 59). La psicología social fue renovada por cuanto se orientó a la comprensión de los procesos de grupos, así como a la conducta colectiva, el autoconcepto y la personalidad.

En antropología la dimensión colectiva de la identidad se encuentra asociada a movimientos sociales, las ONG, reivindicaciones regionales y migraciones, y se refiere a los sujetos en interacción social, particularmente en la esfera subjetiva de los actores sociales. En sociología, se evocan los trabajos de Alain Touraine y Alberto Melucci, los cuales articulan y dan consistencia a los movimientos sociales; los de Jürgen Habermas acerca de la acción comunicativa, y Gilberto Giménez como un atributo de los actores sociales. Desde una perspectiva dinámica, la identidad colectiva se construye en un contexto histórico particular en el cual los sujetos reelaboran los elementos culturales del grupo (Maldonado y Hernández, 2010).

En el campo de la sociología, el concepto de identidad tiene sus raíces en un cuestionamiento del objetivismo durante las décadas de 1960 y 1970, en las cuales ampliaron su presencia los temas de la subjetividad de los actores sociales, la intencionalidad de sus acciones y la elaboración de la perspectiva desde el sujeto. El tema de la identidad social estuvo asociado con la integración social y la "personalidad social". La identidad supone cohesión social; contrario sensu la insolidaridad, los déficits en la comunicación o los desajustes en la organización significan debilidad de la identidad y, por tanto, riesgo sobre su existencia, ya que prima el individualismo desbordado y el egoísmo que obstruyen los sentimientos colectivos.

En conclusión, se ha comprendido que "la perspectiva de la identidad social (...) puede considerarse, sin ningún género de dudas, como uno de los marcos teóricos más influyentes dentro de la psicología de los grupos y, por tanto, dentro de la psicología social" (Canto y Moral, 2005, p. 60). Desde ese momento, se ha desarrollado una de las variables psicológicas y sociales asumidas con una metateoría interaccionista que cubría diferentes niveles de explicación sean ellos el intrapersonal, el interpersonal, el posicional y el ideológico, con lo cual se daba un paso fundamental para evitar el reduccionismo que había caracterizado a trabajos anteriores. El autoconcepto se deriva de la pertenencia a grupos sociales y ellos se valoran con la participación de los individuos. La relación recíproca se ha enriquecido en la vida cotidiana y también en los análisis.

Dados los argumentos anteriores, la identidad de la universidad se examina desde ángulos complementarios, así: a) es una construcción; b) una construcción de sentido; c) sentido que se inscribe en el ámbito cultural; y d) cuyo significado tiene prioridad sobre otras fuentes de sentido. Subrayar estos cuatro aspectos es crucial para la comprensión de la dimensión del proyecto en tanto discrimina los ítems que lo fundamentan y propone una línea de pensamiento.

\section{Es una construcción}

Como construcción, se sigue la teoría práctica o teoría de la práctica de Pierre Bourdieu que se anuda al concepto medular de habitus (Bourdieu, 1997; 2007; Capdevielle, 2011; Ferrante, 2008; 2010). En esa práctica se incluyen las transformaciones de la economía solidaria y del cooperativismo como las derivadas de la "Declaración de Identidad Cooperativa”, adoptada por la II Asamblea General de la Alianza Cooperativa Internacional (ACI) que se realizó en 1995 en Manchester. Luego, se parte de las prácticas, especialmente en el trabajo comunitario como el lugar de aprendizaje cultural y un instrumento de formación de las identidades colectivas en una relación estrecha con otras dimensiones como la identidad de empresa, identidades profesionales, identidad política e identidades personales (Berger y Luckmann, 1998; Chevallier, 1994). Se dejan a un lado las definiciones funcionalistas relacionadas con el concepto de estabilidad y de orden y, a cambio, se prefiere el concepto de continuidad dentro del cambio en una construcción de significados múltiples en diferentes niveles de la organización (Gomes, 2010; Sveningsson y Alvesson, 2003).

\section{Es una construcción de sentido}

La identidad organizacional es el fruto de un proceso de negociación y de ejercicio de estrategias transaccionales en la doble vía de los actores con la organización y de los actores entre sí en el propósito de constituir un "nosotros" colectivo que, a su vez, da fuerza y legitimación a la identidad institucional. Luego, el papel social de la interacción es decisivo para 
comprender la organización universitaria (Artese, 2012). No se desconocen sino, al contrario, se involucran los cambios que ocurren en el entorno por cuanto ellos contribuyen a dotar o a fortalecer la conexión de sentido que requiere la identidad para anclarse en la organización. Experiencias recientes en América Latina serán un referente indispensable (Alter, 2001; Cortés, 2011; Dubar, 1991; Mollis, 2003, 2008, 2010, 2012).

Las diferentes formas de la identidad cobran sentido cuando ellas han sido construidas por la organización, en la dinámica colectiva, pero también y al mismo tiempo por sus integrantes cuando ellos construyen para sí esa identidad, lo que los hace participar de un elemento común (Barbé, 1984). Esto vale para las identidades personales o individuales, para las identidades colectivas, las identidades profesionales, las identidades religiosas, las identidades étnicas y las identidades nacionales, dada su pertenencia al ámbito del Estado-nación o a una determinada cultura (Giddens, 1996; Smith, 1997). Por esta vía, en la actualidad, la identidad cubre los géneros, los roles y el estatus, así como las imágenes atribuidas a personas o a colectividades. En este orden de ideas, las identidades son "depósitos de latencias" por cuanto ellas encierran disposiciones subjetivas para la acción, tal como las analiza el sociólogo estadounidense Robert Merton (1980). Un análisis ex post facto de sucesos y procesos que constituyen la historia de la universidad permite no solo descubrir la identidad sino expandirla, magnificarla y mostrarla en un primer plano.

\section{Es una construcción que se inscribe en el ámbito cultural}

La identidad organizacional está circunscrita al ámbito de su operación. Sin embargo, está vinculada con su entorno directo e indirecto. Por esta razón, un aspecto que ha de tenerse en cuenta es la evidencia histórica de que las organizaciones son, en ocasiones, receptoras de identidades preconstituidas $\mathrm{y}$, desde luego, no necesariamente sus productoras directas sino sus herederas (Chevallier, 1994). Este es el caso de la Universidad Cooperativa de Colombia con respecto a Indesco, transformado y prolongado en la universidad. Por esta vía se presenta un problema epistemológico con respecto a la "cultura corporativa" que es inseparable de los valores sociales, de la política interna y de las relaciones de poder.

\section{Cuyo significado tiene prioridad sobre otras fuentes de sentido}

La identidad es un conjunto de referentes materiales, sociales e intersubjetivos que articulan la identificación tanto de las personas como de los grupos a la dinámica que adopta la organización. La identidad construye peldaños superpuestos en niveles diferenciados: unos son los referentes individuales, otros son los grupales y otros los institucionales vistos desde dentro o desde fuera de una organización. Son identidades sucesivas que se estructuran entre sí para que sean reconocidas por los actores que intervienen dentro de la organización o que se encuentran en el exterior, pero se relacionan con ella (Beck, 1996; Chevallier, 1994; Larraín, 2005; Schütz, 1964a, 1964b). La dinámica que toma la organización en su historia indica las precedencias y los factores que inciden en la formación y en el mantenimiento de la identidad. La reconstrucción de los elementos dentro de la totalidad en la cual se encuentran integrados es un camino ideal en la reconstrucción ex post facto de la identidad (Giddens, 1995).

Con Francois Dubet, se reconoce que "existen tantas dimensiones de la identidad como lógicas de acción social. A la vez, la noción de identidad no posee unidad y no permite explicar las conductas extremadamente diversas, cuando no opuestas" (Dubet, 1989, p. 545). El foco de atención en la identidad no necesariamente tiene el resultado de la claridad, puesto que es posible que algunos elementos resulten confusos o huidizos cuando se les quiere concretar, como son aquellos que se focalizan hacia la igualdad o hacia la diferencia. Ellos no se consideran pertinentes para los objetivos que se han planteado por cuanto se corre el riesgo de dispersarla en este ejercicio intelectual. Como planteaban Aguado y Portal hace 24 años, "para comprender la identidad como un proceso social, es menester contextuarla" (1991, p. 31). Eso es precisamente lo que quiere decir adaptarla a las condiciones del objeto que es la identidad de la universidad en sus condiciones sociohistóricas y culturales. Desde luego, la extensión del concepto cubre solo la universidad por tratarse de un análisis con objeto definido en el tiempo y en el espacio.

Una guía de este estudio ha sido Néstor GarcíaCanclini, quien refiere el concepto de identidad a la producción, reproducción y transformación del sentido, es decir, el significado, a fin de proponer una 
conexión de significado entre cultura, identidad e ideología (1982, p. 41). En este contexto, la identidad social es una construcción de sentido social, es decir, es una construcción simbólica que recoge el sentido colectivo de prácticas y construcciones de ideas, experiencias significativas para los individuos y la colectividad.

Desde luego, la contextualización de la identidad remite a "procesos, que no son sino procesos sociohistóricos, [lo que] constituye una razón necesaria en el análisis social" (Solís, 2004, p. 78). Por tanto, se tienen en cuenta "condiciones generales (lugares históricos, lugares sociales, la interacción social espacio-temporal e intersubjetiva, el carácter de los procesos de adquisición y acumulación de valores, conceptos, etc.) en las que toma forma el sentido" (Solís, 2004, p. 79). El "sentido" tiene una distinción dual, es decir, se refiere a nociones como "reservas de sentido", "comunidad de sentido" y similares, que son construcciones desde las subjetividades, y al mismo tiempo son expresiones de un fenómeno social de constitución de sentido. El planteamiento se deriva de Alfred Schütz con sus depósitos de sentido, comunidad de sentido, islas de sentido e importación de sentido, entre otras, así como el "acervo social del conocimiento", lo cual encuentra su génesis en la actividad de los sujetos para otorgar significados a objetos o acciones.

Un elemento vinculado a la identidad es la ideología. En el caso del cooperativismo y las formas solidarias, la justicia, la equidad, la solidaridad, el respeto por el "otro" y los derechos humanos son valores que circulan en las organizaciones y sostienen la justificación de su existencia y funcionamiento. La identidad ha sido construida en procesos de identificaciones históricamente afirmados en la función de otorgar sentido y direccionamiento a un grupo social, a una organización o a personas individuales. De ellas se pide identificación con esos valores, así como fidelidad en sus prácticas dirigidas a fortalecer los procesos ideológicos que irrigan todas las actividades. Por tanto, se reconoce que "la ideología es una dimensión de la cultura. Sin ideología no hay identidad, aunque ésta no se agota en la ideología" (Aguado y Portal, 1991, p. 32). En otras palabras, la identidad tiene un fuerte componente de ideología, pero esta no cubre todas las posibilidades de la identidad como se examinó antes. No ocurre una transposición de términos en el sentido de que identidad sea asimilable a ideología y esta, a su vez, a identidad.
Como se ha mencionado, hay dos caras o dos maneras de concebir la identidad: una como compromiso y otra como autoproducción por el trabajo, pero ambas están llamadas a fortalecer la conexión de las personas individuales con la identidad institucional o, como lo expresan Berger y Luckmann, "la identidad se define objetivamente como ubicación en un mundo determinado y puede asumírsela subjetivamente sólo junto con ese mundo" (1998, p. 168). No coinciden todos con esta aseveración, ya que consideran una salida diferente. Por un lado, en el caso de Daniel Bell, aparece el tema del nihilismo mientras que, por el otro, surge la salida del narcisismo y el individualismo como manifiestan Lasch y Sennett (Dubet, 1989, p. 542). La línea de búsqueda se encuentra en la coherencia entre las guías iniciales de los fundadores, quienes se han encargado de ser los referentes a fin de mantener y enriquecer en el tiempo la vocación original y provocar transformaciones que concuerden con la filosofía marcada inicialmente.

Con Berger y Luckmann, se puede concluir que "la investigación empírica sobre la relación de las instituciones con los universos simbólicos legitimadores contribuirá grandemente a la comprensión sociológica de la sociedad contemporánea" (1998, p. 231); en este caso, la comprensión de la identidad propia de la Universidad Cooperativa de Colombia en el doble entorno de las organizaciones solidarias y de las universidades con las cuales ha sellado su compromiso institucional. Su existencia de 58 años, desde la constitución de Indesco hasta la actualidad, ha mostrado sus rasgos específicos por los cuales ha sido reconocida dentro del ámbito de las instituciones de educación superior, del sector de la economía solidaria, del Estado y de la sociedad civil, lo que equivale a decir el sustrato del sentido original y la fundamentación que ellos han tenido para respaldar la identidad institucional en la doble perspectiva del "adentro" y del "afuera" de la organización.

\section{Las trayectorias de la universidad}

La Universidad Cooperativa de Colombia ha consolidado una identidad que hace la diferencia con otras organizaciones de educación superior que funcionan en el país. Apenas había pasado el periodo populista del general Gustavo Rojas-Pinilla y se iniciaba el Frente Nacional, cuando los fundadores pusieron en 
marcha un proyecto que a mediados de la segunda década del siglo xxI aún permanece vigente. Rymel Serrano-Uribe, Henry Serrano-Uribe y Carlos UribeGarzón fueron los gestores que idearon el derrotero que tomaría la nueva organización. Ellos vivieron los cambios en los modelos de desarrollo del Estado, los vaivenes de las empresas privadas, las bonanzas y sus declives, mientras el cooperativismo y las organizaciones de espíritu solidario salían a flote y ganaban protagonismo con su gestión emprendedora. La terminación de un periodo de confrontaciones políticas, militares y armadas entre sectores del poder dirigente que se llevaron por delante a la población civil, fue un avance civilizatorio. Se abrió un espacio para el florecimiento de las organizaciones civiles en un ambiente de "desarrollo económico y social". Las cooperativas encontraron un camino despejado para su acción.

Las universidades, por su parte, buscaban mecanismos de adaptación en una transformación inédita en la historia pasada, y entraron con vigor a responder a las demandas de ampliación de la cobertura y de llenar las expectativas del Estado y de la sociedad por acceder a la educación superior. El nacimiento de Indesco fue paralelo en el tiempo al de la Universidad de los Andes, con dos concepciones, dos orientaciones y dos objetivos, pero ambas organizaciones con la vocación de servir a la sociedad a su manera. La interpretación sobre el papel en la sociedad clarificaba sus límites y sus audiencias: mientras una se enfocaba en servir a las élites, la otra buscaba abrir oportunidades a los sectores populares. La historia, como ha dicho Immanuel Wallerstein, "no está al lado de nadie" (Coolen, 2002), porque las opciones están abiertas. La insurgencia guerrillera, por su parte, como expresión de variadas ideologías de izquierda nacionalista e internacional, contribuyó a dispersar los proyectos sociales y a fracturar el sentido de la política. Las ideologías reinantes filtraban las posiciones políticas y encausaban sus proyectos en medio de las luchas internas por el poder, en una historia construida a pedazos y en un ambiente internacional que respiraba la confrontación internacional en medio de la Guerra Fría. El Frente Nacional no logró la conciliación ni la terminación del conflicto (Rojas y Camacho, 1973). La segunda mitad del siglo xx fue el escenario de las luchas políticas, pero también sociales y culturales, junto con los movimientos armados de los diferentes orígenes, objetivos y estrategias, desde los comunitarios y étnicos, pasa por los nacionalistas, los contrarevolucionarios y los de la guerra prolongada, hasta los vinculados al narcotráfico y a la delincuencia común, al lado de los promotores y agentes de la corrupción que defraudaron a particulares, a las organizaciones y al ciudadano del común. Las agitaciones fueron de todo orden en un ambiente enrarecido para la conciliación y la búsqueda de un diálogo entre sectores distantes.

La naciente universidad logró avances significativos en medio del clima descrito. De las instalaciones del Colegio Moreno y Escandón, su lugar de origen, pasó a la sede provisional de la carrera $15 \mathrm{n}$. 27-35 y la ubicación definitiva en la avenida Caracas n. ${ }^{\circ}$ 37-63 en 1972, en Bogotá, y se ha expandido por el país. Ha llegado a 18 ciudades en las cuales ha instalado sus sedes para atender a 55000 estudiantes por semestre y a 500 aprendices, con 4500 profesores y 3000 administrativos. Esto le ha permitido hacer entrega a la sociedad de 142000 graduados desde 1966, año en que salieron los primeros profesionales, hasta el 2015. Este recorrido ha sido el resultado de la consolidación de una organización cimentada en principios de solidaridad mediante mecanismos de interacción con cooperativas y organizaciones sociales y políticas.

\section{El Indesco de la vocación originaria}

Las organizaciones que ofrecían programas educativos de nivel superior eran públicas o privadas, bien fueran ellas religiosas o bien laicas. Sin embargo, esta categorización agotaba las posibilidades. Desde el inicio, la idea estaba clara en sus gestores: no se ambicionaba replicar las experiencias de otras instituciones, sino marcar un camino propio, lo que le daría la identidad y el sello cooperativo. Esto no significaba encerrarse en un gueto, impulsar procesos solo para iniciados ni conquistar partidarios a una secta cerrada y confesional. Por tanto, los primeros desarrollos de Indesco como asesor de cooperativas, articulador de la educación y estimulador de organización se debían sostener y fortalecer. Los fundadores tenían conciencia de cómo un proyecto de estas dimensiones debía ganar espacios de cimentación en la sociedad no conquistados aún en la historia precedente. La legitimidad se consiguió cuando, con fundamento en la legislación cooperativa vigente (Decreto-Ley 1598 de 1963), la Superintendencia Nacional de Cooperativas reconoció en Indesco una institución auxiliar del cooperativismo desde 1968, y cuando el Ministerio de 
Educación Nacional, en 1972, lo caracterizó como un centro de investigaciones cooperativo-educacionales. Estas manifestaciones del Estado se usaban como indicadores positivos del camino que debía construirse colectivamente.

Los planteamientos, en consecuencia, se orientaban a la conformación de agentes de cambio en la sociedad, a apoyar la organización de las grandes mayorías con déficits de los bienes y servicios, a activar la participación popular y a infundir motivación en los socios a través de campañas educativas y de un auténtico liderazgo social que representara los intereses de los socios.

En el fondo de estos planteamientos se camuflaba la motivación de que las cooperativas fueran instrumentos de desarrollo que produjeran cambios fundamentales en las estructuras generadoras de atraso en la sociedad colombiana. La caracterización del "subdesarrollo" identificaba la falta de participación activa y pasiva como uno de sus factores determinantes. El Indesco promovía la organización como la fortaleza social y cultural. La concepción de la educación se evidenciaba como "un proceso por el cual se crea conciencia en el individuo sobre su responsabilidad como miembro de una organización comunitaria, desarrollando en él actitudes de cambio de una sociedad individualista en una sociedad solidaria", según un informe de un encuentro de directivos, profesores y estudiantes en Santandercito, corregimiento del municipio de San Antonio del Tequendama en el departamento de Cundinamarca (Universidad Cooperativa de Colombia-UCC, 1971). Esta frase resumía los planteamientos del momento.

Era el momento del Banco Mundial, de la oeA y de las ideas de Lauchlin Currie, pero también de la Cepal, organizaciones que dirigieron la política económica y social en la región latinoamericana (Villamizar, 2013). Las cooperativas y el movimiento solidario se alimentaban de los trabajos de Antonio García (1969; 1972; 1979), de Sunkel (1970), Furtado (1974), y de Cardoso y Faletto (1977), entre muchos otros en la abundancia de la literatura que circulaba en América Latina. Rymel Serrano tuvo oportunidades de establecer contactos nacionales e internacionales proporcionados por su vinculación al sector, en el cual ha desarrollado su vida. Una característica de los fundadores es que ligaron en una unidad vida y compromiso social. Con esto confirmaron los análisis de teóricos de la sociología que estudiaron el fenómeno y vincularon la vida personal con la producción intelectual en un contexto de "estructura de oportunidades". Los fundamentos se encuentran principalmente en Robert King-Merton, sobre todo en La estructura de la ciencia (1977), y en Una vida de aprendizaje (Hunt, 1996; Cataño, 1997). Otros sociólogos como Mills (“Artesanía intelectual”, en La imaginación sociológica, 1961), Peter Berger y Thomas Luckmann ( La construcción social de la realidad, 1998), Karl Mannheim (El hombre y la sociedad en la época de crisis, 1969), así como en Ensayos de sociología de la cultura (1957), han desarrollado el mismo pensamiento. De igual modo, Orlando Fals Borda en el caso colombiano (Borja, Pineda y Vizcaíno, 2012, 2014). La vida personal se conjuga con la actividad pública, social y educativa.

No era solo el caso particular de los gestores, sino que ellos tuvieron la capacidad de contagiar a otros con la fuerza de la motivación y de la convicción. Así estaban dedicados todos, entre ellos José del Carmen Moreno, Vicente Murraín y Álvaro Flórez. Pero detrás estaba el apoyo ideológico, teórico, metodológico y procedimental, político y programático de personas como Antonio García, Orlando Fals Borda, Hernando Ochoa, Fernando Urrea, Crisanto Velandia-M. y otros que conformaban el equipo de trabajo cercano a los directivos, dirigidos por Francisco Rodríguez y Marco Antonio Mansilla, precisamente formados en Francia en economía social y organizaciones cooperativas. No había congreso cooperativo o reunión cooperativa de alguna trascendencia para el sector en la que no estuviera presente Indesco, porque el cooperativismo formaba parte esencial de la universidad y se concretaba en una estrecha relación con las cooperativas, con la Superintendencia, con el Ministerio de Educación Nacional y con organismos internacionales, como la Fundación Konrad Adenauer de Alemania, a la cual debe la universidad un decidido apoyo técnico, un soporte financiero y una ayuda administrativa en el momento de despegue como universidad.

El edificio central de la avenida Caracas $n .^{\circ}$ 37-63 de Bogotá fue adquirido por la fundación y se entregó a la universidad en 1973. La fuerza de la educación estaba, desde luego, acompañada de organización y de acción dentro del sector, y la visibilidad ganada por Indesco permitía canalizar esfuerzos provenientes de organizaciones del país y del exterior que respaldaban los proyectos en la medida en que la doctrina cooperativa era reconocida en ellos 
y avalada por organismos internacionales como la Alianza Cooperativa Internacional (ACI) y el Consejo Mundial de las Cooperativas de Ahorro y Crédito (World Council of Credit Unions- Woccu; Uribe, 1978, 2005).

\section{La ruptura institucional}

Todo lo anterior indica que Indesco era un proyecto en dos dimensiones. Era, a la vez, local en la medida en que estaba dedicado a ser parte de la solución de problemas sociales (como la educación en la geografía social colombiana) y, al mismo tiempo, internacional por cuanto atendía orientaciones de la doctrina cooperativa que se irrigaba de un país a otro, y de un continente a otro. Era un proyecto abierto con conectores locales, nacionales, regionales e internacionales, como lo son los principios de base que eran la solidaridad y la integración sin fronteras. La globalización que hoy está frente a nosotros era tenue y no había tomado la fuerza de huracán que presenta en la actualidad. Era, sin embargo, un momento en que la institución, por la fuerza de los hechos, estaba llamada a diversificarse.

La estructura interna debía ramificarse a fin de perseguir los objetivos tradicionales y los nuevos. Indesco, dedicado a la asesoría y orientación cooperativa, debía crear su propio espacio para que la Universidad se desarrollara en el suyo. Dos instancias administrativas - una dedicada a prestar servicios educativos y de asesoría a cooperativas y otra a la nueva universidad-diversificaron los objetivos. Era una solución al crecimiento que se convirtió en un conflicto de varios meses entre dos sectores: uno que se proponía mantener una sola organización centrada en el cooperativismo (de los fundadores y defensores de la institucionalidad), y el otro que prefería tomar el camino de la educación superior (de algunos decanos, profesores y estudiantes alimentados por orientaciones ideológicas de izquierda liderados por una posición trotskista). Esta última posición fue reconocida como vencedora y, en consecuencia, toda su actividad se volcó sobre el interés de ofrecer programas académicos dentro del espacio de la universidad. Se prefirieron programas de nivel profesional superior a cambio de los niveles técnico y tecnológico con el cooperativismo que constituía su núcleo, como planteaba la opción de los derrotados.

\section{La intervención del Icfes}

El Instituto para el Fomento de la Educación Superior (Icfes), en su carácter de entidad del Estado y con la fuerza de la norma de la suprema vigilancia y control en sus manos, llevó a una decisión que rompió los cimientos de los enfoques que habían sido creados por la naciente universidad. Los seis años de construcción colectiva se derrumbaron con el apoyo del Estado a favor de grupos de izquierda con un Gobierno que iniciaba el Posfrente Nacional. Es una paradoja histórica. La alternativa de universidad de los recién llegados llevó, en primer lugar, a desmontar los proyectos que conjugaban cooperativismo, proyección económica y social y formación profesional con competencias definidas para la progresividad de cada nivel. La estructura académica original tenía un plan por ciclos que fluían de la siguiente manera:

- Primer ciclo. De fundamentación integral, común para todos los estudiantes con duración de dos semestres, 44 créditos y con un diploma final de "Auxiliar en Cooperativismo".

- Segundo ciclo. Diversificado en dos áreas: organización de la comunidad y técnicas contables, con duración de dos semestres, con 88 créditos acumulados y con diploma final de "Experto en Cooperativismo".

- Tercer ciclo. Especializado en uno de cuatro campos: educación, desarrollo de la comunidad, economía social y administración, con duración de cuatro semestres, con 176 créditos acumulados y con un diploma de "Licenciado".

- Cuarto ciclo. Profesional en cuatro especialidades: administrador educativo, sociólogo, economista social y gerente, con duración de dos semestres, con 220 créditos acumulados y con un diploma de "Profesional" (Vizcaíno y Muñoz, 2015).

La gradualidad del plan, los diplomas intermedios y la habilitación en los niveles de preparación otorgaban a la formación en la Universidad Indesco una característica que la identificaba y la distinguía de las otras instituciones de su género. Algunas particularidades eran propias de la concepción curricular. Por ejemplo, se tenían laboratorios a lo largo de la formación - al principio de orientación profesional-, de acuerdo con el área o el campo seleccionado por el estudiante. 
Se tenía programada investigación en cada uno de los ciclos, de carácter general y de fundamentación en los primeros semestres, y de acuerdo con la especialización, en los últimos. Se desarrollaba el cooperativismo en todos los ciclos según los requerimientos del diploma que se expedía al finalizar cada uno de ellos. Sociología era una asignatura básica para comprender los fenómenos sociales con los cuales debería tener relación el egresado en cualquiera de las modalidades.

A medida que los ciclos se afianzaban, se impartían asignaturas comunes y asignaturas electivas de acuerdo con las áreas y los campos elegidos. La propuesta, en conjunto, era una anticipación práctica de lo que sería reglamentado posteriormente por el Decreto-Ley 080 de 1980 como las carreras por ciclos y su desarrollo en unidades de labor académica (ULA). En la primera década del nuevo siglo, a partir del 2005, el Ministerio de Educación Nacional ha impulsado la idea según la cual las universidades desarrollen competencias entre sus estudiantes. El fundamento ha sido traído del exterior como novedad. Así lo dicen algunas fuentes de organizaciones, principalmente Eurydice (2002), el Proyecto Tuning de Europa (2005), la Organización para la Cooperación y el Desarrollo Económicos-OeCD (2007, 2009), el Banco Mundial (2007), e investigadores como Hambur (2002), Barrie (2004, 2006), Gilbert (2007) o Perenoud (2008), como se citan en Ministerio de Educación Nacional (2011). Con estos y otros lineamientos de similar orientación, se ha generalizado en el país el tratamiento de competencias en la educación superior. Así, la competencia se entiende como:

Una mezcla de características de otras competencias, tales como el aprendizaje autónomo, el pensamiento innovativo y el aprendizaje permanente, solo que aquí no se enfatiza tanto la capacidad innovadora cuanto la capacidad de realizar transferencia de conocimientos y habilidades de una situación a otra. Igual que con el aprendizaje permanente, su desempeño solamente puede comprobarse durante el recorrido de la historia ocupacional de cada egresado. (Ministerio de Educación Nacional, 2011)

El enfoque acepta incorporar las competencias previas con las asimiladas en el proceso de formación y las que el desempeño lleve de la práctica a la praxis innovadora. Las continuidades entre unas competencias y otras suponen un aprendizaje de asimilación y adaptación a las condiciones específicas que demanda el ejercicio profesional. No son solo transferencias, sino renovación de aprendizajes previos de acuerdo con las exigencias del medio. En el caso del enfoque adoptado por el Indesco de la época inicial, se proyectaba a los cambios de la modernidad y por los procesos que el desarrollismo impulsaba en el país. En el lenguaje de hoy se podría decir que las competencias desarrollan la autonomía en dos líneas de pensamiento y de acción. Por un lado:

Organizar información, consultar, deducir, inducir, resumir, representar, revisar, cambiar de perspectiva de análisis, ordenar el proceso, analizar instrucciones [y por el otro] capacidad de analizar, corregir y mejorar los procesos propios de aprendizaje, para lo cual es necesaria una reflexión permanente sobre las estrategias adoptadas - cognitivas y metacognitivas - y sobre los resultados obtenidos con las mismas, en términos de eficiencia y calidad del aprendizaje realizado. (Ministerio de Educación Nacional, 2011)

En suma, reflexión-acción-reflexión para una proyección eficiente y eficaz.

Desafortunadamente, los visitadores del Icfes, a nombre del Estado, impusieron la uniformidad como criterio de los programas y de las carreras con el supuesto de que la unanimidad era el ideal de la formación, a cambio de lo que se ha desarrollado posteriormente que es la diversidad y la apertura. Se perdió una oportunidad de búsqueda de alternativas a los sistemas convencionales porque los criterios generalizados se derivaron de la asesoría de Rudolph Atcon con su plan básico planteado en La universidad latinoamericana (2005/1961). Las controversias fueron múltiples en sectores institucionales, de intelectuales y estudiantes, sin que fueran escuchadas (Ocampo, 1981). La reacción del Gobierno fue la decisión de su implantación. Lo que había sido una innovación de transcendencia fue sepultada de manera unilateral. La transacción de la joven universidad con las exigencias de los visitadores oficiales fue llamarlos para que se vincularan como decanos de los programas de Administración Social, Economía Social, Desarrollo Social y Educación Social que se cambiaron, respectivamente, por Administración de Empresas, Economía, Sociología y Administración Educativa, las cuatro carreras que iniciaron la vida académica de la institución. La 
lección quedaba clara: innovaciones no eran aceptadas porque rompían un esquema que se presentaba como autosuficiente.

Otra decisión crucial en el desarrollo de la joven universidad fue suprimir las conexiones nacionales e internacionales con el sector solidario, especialmente con la Fundación Konrad Adenauer, la cual prestaba asistencia técnica y financiera. Por esta vía se suprimieron los canales de financiación, cuyo resultado a corto plazo fue la iliquidez y la precariedad en sus fondos. No hubo dineros para el funcionamiento cotidiano y los docentes tuvieron que ceder sus emolumentos para que la organización se mantuviera y se evitara una nueva intervención del Icfes. En efecto, la visita de esta entidad en los años 1974-1975 marcó el cambio hacia esquemas convencionales de carreras independientes, con planes segmentados y autónomos de estudio, administración propia, docentes asignados y actividades académicas compartimentadas, como era la recomendación de Atcon (2005/1961), que fue legitimada por el Estado.

La organización de facultades y de programas marcó una separación vertical y anuló la horizontalidad en la gradualidad, con lo cual se liquidó la experiencia educativa, académica y pedagógica que otorgaba identidad a la institución. Las sedes de Bogotá, Medellín, Bucaramanga y Barrancabermeja, que participaban de un mismo proyecto educativo, se dieron su propia organización y actuaron durante varios años como entidades relativamente independientes, con escasos lazos de vinculación, representados en una instancia que se denominó "Consejo de directores" y que no fue suficiente para soportar y ejecutar un solo plan de acción. La aprobación de cada programa, así como la gestión administrativa y académica, eran particulares de cada seccional, lo cual debilitaba los lazos internos y el apoyo entre unas sedes y otras para soportar y comprometerse con un solo proyecto educativo. La identidad se construyó en las sedes regionales y sus límites no les permitieron prolongarse a una universidad de carácter nacional (Vizcaíno y Muñoz, 2015).

Las críticas al esquema de compartimentos estanco de las carreras y facultades, la separación abrupta de unidades administrativas, el enclaustramiento de las disciplinas, las fronteras cerradas, el bloqueo de comunicación con otros espacios académicos, la exclusividad profesoral a roles vinculados con un segmento del conocimiento, todo esto ha sido puesto en cuestión en la dinámica posterior de las universidades. Los defensores de la integración del conocimiento, quienes promueven la interdisciplinariedad y la transdisciplinariedad, quienes están interesados en explorar el campo de las fronteras comunes y de generar espacios nuevos de conocimiento son quienes manifiestan hoy su desacuerdo con las viejas prácticas académicas, como las que fueron puestas en discusión cuando se construyó la propuesta educativa integrada de Indesco.

La experiencia colombiana de años y décadas siguientes demostró que el Icfes cumplió el papel de frenar el desarrollo de una iniciativa como la de Indesco, y aplazó lo que en la actualidad se acepta con pocas excepciones. La camisa de fuerza impuesta aún está vigente y también se mantiene la crítica, ahora con mayores argumentos (Giddens, 2000; Pacheco, 2005; Wallerstein, 2001, 2005; Zabludovsky, 2007). La fase histórica llegaba a su fin con la debilidad y casi inexistencia de Indesco, ya que se la había invisibilizado en el conjunto de las instituciones de su género. El calificativo despectivo y excluyente de "universidades de garaje" y "universidades de masa" que provenía de un modelo de universidades de élite descalificaba una acción en la cual se atendía población de sectores sociales que no alcanzaban a acceder a las universidades de un estrato más alto al de su origen. Se discriminaba, es cierto, la institución, pero, sobre todo, la población que, de otra manera, no podía hacer uso del servicio de educación superior. El argumento a favor de la Universidad Cooperativa era que atendía a una población excluida del sistema regular, y con ello no competía con la gran universidad. Esto mostraba la diversidad de opciones a cambio de los intentos de buscar la uniformidad de las instituciones. Se imponía la especificidad de la identidad institucional en la subsistencia frente a los ataques de sectores altos de la sociedad, de las universidades de mayor prestigio y del propio Estado.

Un estudio realizado en la sede Bogotá sobre Universidad: exclusión y desigualdad (Vizcaíno y Amaya, 2006), analizó los dos fenómenos con sus consideraciones filosóficas, políticas y sociológicas. Se asumió el planteamiento que sostiene que la desigualdad es, ante todo, un fenómeno de carácter socioeconómico, mientras que la exclusión se considera de orden sociocultural. La distinción se remite a una precisión hecha por Boaventura de Sousa-Santos, quien señala: 
Si la desigualdad es un fenómeno socioeconómico, la exclusión es sobre todo un fenómeno cultural y social, un fenómeno de civilización. Se trata de un proceso a través del cual una cultura, por la vía de un discurso de verdad, crea la interdicción y la rechaza. El sistema de desigualdad se basa, paradójicamente, en el carácter esencial de la igualdad; el sistema de exclusión se sustenta en el carácter esencial de la diferencia... el grado extremo de la exclusión es el exterminio y el grado extremo de la desigualdad es la esclavitud. (Como se cita en Fleury, 2003, p. 171)

El fundamento teórico según el cual la ciudadanía es una forma adecuada para establecer la igualdad se argumenta en Ciudadanía y clase social, de Thomas Humphrey Marshall, en sus conferencias en Cambridge en 1949 (1997), en las cuales también trata la forma específica de desigualdad que es la desigualdad social. El análisis se remonta a la historia del proceso de conformación de la ciudadanía como modo de acceder a la igualdad social y, al mismo tiempo, la clase social como aquel sistema de desigualdad. Las diferencias en el acceso a la educación pueden provenir de motivos individuales y habría que tratarlos como tales. Pero las diferencias provenientes de la misma sociedad son cuestionables desde una postura política relacionada con el carácter de la ciudadanía. Cuando a estas diferencias de la sociedad se adicionan diferencias en la cultura, el problema adquiere otras dimensiones y estas se convierten en un multiplicador de más diferencias. Estos son los aspectos centrales del estudio referenciado que, una vez más, argumenta la necesidad e importancia del rol de una universidad que atiende a una población que, en otras circunstancias, no encuentra los caminos deseables para el acceso a la educación superior.

\section{La Universidad Cooperativa de Colombia}

En 1982, se realizan los trámites oficiales para el reconocimiento como Corporación Universidad Cooperativa de Colombia y ajustarla a los requerimientos del Decreto-Ley 080 de 1980. Se reforman sus estatutos, se da una organización actualizada que integra las sedes en una estructura centralizada, se toman medidas administrativas y financieras para superar los déficits, se consiguen apoyos financieros del Estado, se reorganizan los planes de estudio y se construye una imagen renovada de lo que ha sido su tradición. Indesco queda subvalorado y sus operaciones tienen serias limitaciones para producir resultados. Su prestigio y aun su existencia estuvieron escondidos y no aparecieron oficialmente en la escena de la universidad sino hasta 1997, cuando Rymel Serrano regresó a la dirección de Indesco para darle un impulso que lo ha traído hasta la segunda década del nuevo siglo.

La debilidad no solo provenía de la universidad. Tal como las cooperativas de la segunda década del siglo xx en Colombia, la Universidad Cooperativa ha tenido un origen popular por su enfoque y objetivo, con una concepción de organización estadocéntrica por cuanto su funcionamiento depende del Estado a causa de la suprema inspección y vigilancia que ejerce sobre ella. Dos etapas se pueden identificar en su vida institucional: la primera va desde su creación hasta 1992, y la segunda a partir de la Ley 30 de 1992, por la cual se estableció la autonomía universitaria. En la primera etapa, las universidades debían, entre otras cosas:

- Solicitar la licencia de funcionamiento al Icfes.

- Tramitar la aprobación de los programas académicos por un periodo definido.

- Solicitar visita del Icfes para ampliación de la aprobación de los programas.

- Atenerse a las decisiones del Icfes sobre la orientación, la duración, la estructura académica y las características metodológicas y didácticas de los programas.

- Ajustarse a las decisiones del Icfes sobre graduación de estudiantes y otorgamiento de títulos.

La segunda etapa abrió un espacio a la autonomía. A pesar de que el Estado mantuvo la vigilancia y el control, gran parte de la vida académica ocurre bajo la figura de la autonomía universitaria, que se concreta en:

- La administración y dirección de la Universidad.

- El diseño y la oferta de programas académicos, con la correspondiente información al viceministerio de Educación Superior.

- La vigencia del estatuto docente y el reglamento estudiantil.

- El diseño de propuestas de ampliación de la oferta de programas.

- La orientación de las características específicas de los programas en su enfoque, fundamentación, población atendida, orientación y estructura curricular, metodologías y didácticas, 
sistemas de evaluación y acompañamiento a los estudiantes.

- El desarrollo de la investigación.

- La proyección institucional.

- La decisión sobre si se asume la acreditación de programas y la acreditación institucional.

Sin embargo, las normas están presentes y tienen no solo poder orientador, sino también poder restrictivo, de acuerdo con la interpretación y aplicación a sucesos específicos. Las normas han proliferado en los años recientes. Solo unos ejemplos son ilustrativos:

Constitución Nacional de 1991.

- Ley 30 de 1992 de Educación Superior.

- Decreto 1403 del 21 de julio de 1993, por el cual se reglamenta la Ley 30 de 1992.

- Ley 115 de 1994 que expide la Ley General de Educación.

- Decreto 1478 del 13 de julio de 1994, por el cual se establecen los requisitos y procedimientos para el reconocimiento de personería jurídica de instituciones privadas de educación superior, la creación de seccionales y se dictan otras disposiciones.

- Decreto 0272 del 11 de febrero de 1998, por el cual se establecen los requisitos de creación y funcionamiento de los programas académicos de pregrado y posgrado en educación ofrecidos por las universidades y por las instituciones universitarias, se establece la nomenclatura de los títulos y se dictan otras disposiciones.

- Ley 749 de 2002 que organiza el servicio público de la educación superior en las modalidades de formación técnica-profesional y tecnológica.

- Decreto 2566 de 2003 que establece las condiciones mínimas de calidad y demás requisitos para el ofrecimiento y el desarrollo de programas académicos de educación superior.

- Ley 1188 de 2008 que regula el registro calificado de los programas de educación superior.

- El Decreto 1295 de 2010 que reglamenta el registro calificado y la oferta y el desarrollo de programas académicos de educación superior.

Estos son ejemplos de las numerosas normas que implican reglamentaciones, aclaraciones, desarrollos en normas subsiguientes que se entienden en un país con mentalidad "santanderista", lo cual significa apego a la norma de tal manera que se le hace imprescindible cuando se trata de argumentar una propuesta o punto de vista, al igual que cuando se ejerce la autonomía universitaria. Por tanto, las instituciones centran su razón de ser tanto en el discurso como en la práctica en la existencia normativa, más que en su propia identidad y en espacios del conocimiento que caracterizan a las universidades. El volumen y las implicaciones de las normas han inundado el ambiente universitario y producido una avalancha que desplazó las tareas fundamentales de docencia, investigación y proyección institucional.

Resulta paradójico que el Estado, por un lado, libere de las normas a las empresas que tienen iniciativa privada para sus transacciones mercantiles y financieras; $y$, por otro, concentre su poder normativo y de control sobre las organizaciones del saber que fundamentan su actividad en el conocimiento científico, al que se le reconoce constitucionalmente, por otra parte, como un espacio de libertad de cátedra y de investigación. El gran salto que está ocurriendo en el mundo actual no es del Estado-nación a un Estado mundial, sino del Estado al mercado, y este no requiere normas para su funcionamiento salvo las que se dé a sí mismo. En consecuencia, el Estado-nación experimenta un vacío de poder que se llena en frentes como la seguridad y el control de los ciudadanos. En otros aspectos, el Estado se convierte en un "zombi" (Beck, 2002b, p. 45) que va y viene sin coherencia definida.

Entretanto, a finales de siglo, con la incursión del espíritu neoliberal, pocas organizaciones cooperativas sobreaguaron mientras las universidades ganaron un espacio antes no experimentado. La masificación en el acceso a la educación superior dio oportunidades a aspirantes de los diferentes estratos sociales, y se abrieron las puertas de la tradicional universidad organizada para las élites con nuevas organizaciones que también atendieron sectores medios y bajos de la sociedad colombiana. Por otra parte, el estatuto general de las universidades que ha sido la Ley 30 de 1992, tan pronto fue expedida recibió críticas y propuestas para su renovación sin que los intentos hayan llegado a su objetivo. A cambio de ello, el Gobierno y las universidades han llegado a un consenso de política que se ha organizado en el documento Acuerdo por lo superior 2034, Propuesta de política pública para la excelencia de la educación superior en Colombia en el escenario de la paz (Cesu, 2014), con una "Introducción” de Edgar Morin. 
La Universidad Cooperativa de Colombia ha construido una trayectoria similar a las demás universidades con diferencias de ritmo, velocidad, orientación y visibilidad en razón de su identidad institucional. Fue la abanderada de la educación superior de la economía solidaria, reconocida por el Estado como institución auxiliar del cooperativismo por Resolución 501 de 1974, emanada de la Superintendencia Nacional de Cooperativas; como centro de investigaciones cooperativo-educacionales por Resolución 2124 de 1972 del Ministerio de Educación Nacional; y como Universidad Cooperativa de Colombia por Resolución 24195 de 1983 del Ministerio de Educación Nacional (Vizcaíno y Muñoz, 2015, p. 126). Sus éxitos en medio de los avatares financieros y de reconocimiento social, tomaron aires renovados para erigirse como la universidad de mayor cobertura geográfica y social del país. A pesar de ello, ha debido disputarse espacios de reconocimiento como el asiento en el CESU, como está establecido en la Ley 30 de 1992, y que solo fue aceptado mediante la Resolución 1850 de 2002, tal como la expidió el Ministerio de Educación Nacional.

La Universidad reconoce que tiene una responsabilidad social con autonomía institucional que le sirve de nicho para articular las funciones misionales de formación, investigación y proyección social. Considera fundamental la producción y circulación de ciencia responsable, la construcción de una nueva ciudadanía a través del fomento de la capacidad de diálogo, la reflexión para el ejercicio democrático y la formación de profesionales con un enfoque centrado en el desarrollo justo y sostenible desde las regiones, sin perder de vista la perspectiva global (UCC, 2005, 2009, 2012).

La Universidad se abre gradualmente a un mundo globalizado con elementos de modernidad como la ciencia, la ciudadanía, el diálogo, la justicia y la sostenibilidad. Conceptos como el de democracia en las cooperativas, "desde los orígenes mismos del movimiento cooperativo, han sido conocidos, difundidos y practicados" (Serrano, 2007, p. 64).

La Universidad ha crecido cuantitativa y cualitativamente, se han ampliado sus servicios, la población servida ha crecido significativamente, las sedes se han ramificado, se han creado zonas y se han establecido instancias de dirección. Contar con 55000 estudiantes atendidos por 4800 profesores es el resultado de un esfuerzo por consolidar el proyecto educativo. Estos son solo indicadores de expansión que son el resultado de su identidad institucional.

\section{Una universidad de cara al futuro}

Los énfasis cada vez más insistentes sobre la calidad de la educación se mantienen en sus lineamientos. Los nuevos retos están al frente: articular la Universidad, vincularla a la sociedad en el nuevo contexto del Estado y de la sociedad, de las nuevas tecnologías y de los procesos de globalización creciente, y de las expectativas de potenciales beneficiarios de los servicios educativos. En este camino, la Universidad ha recuperado para sí al Indesco fundador y lo ha incorporado a su gestión orientada con el espíritu "cooperativo" (Vizcaíno y Muñoz, 2015).

En el nuevo siglo revive Indesco, y surge vigoroso, esta vez de la mano de la Universidad. Si en 1970 la Universidad fue el resultado de una diferenciación estructural de Indesco gestada en su crecimiento, ahora la Universidad, que ha llegado a ser adulta, acoge a su progenitor y le abre un espacio para que retome los hilos de su historia. La reestructuración de Indesco como una dependencia de la Universidad en el nivel nacional (Acuerdo 01, 12 abril del 2007) recuerda su trayectoria ligada a la Universidad y asume que se proyecta sobre este mismo engranaje. La unidad pasa a depender directamente de la Rectoría Nacional, lo que indica la importancia que se le imprime y, por otro lado, la articulación que tiene como política y como acción dentro de la Universidad.

La decisión ha sido un paso significativo por cuanto el cooperativismo se ha reinstalado y hace parte de las asignaturas institucionales en todos los programas académicos. De esta suerte, Indesco ha recuperado su espacio, se ha fortalecido con la renovación e internacionalización de la revista Cooperativismo \& Desarrollo, ha reinventado su misión y ha recogido sus hilos conectores con el sector solidario en el país y en el extranjero. La dirección de Rymel Serrano ha representado de nuevo un liderazgo carismático fundamental.

La Universidad e Indesco han aplicado dos conceptos de autonomía de una manera complementaria. Por un lado, la autonomía sustantiva, entendida como el poder de las organizaciones para definir sus propios objetivos, programas y metas, es decir, el "qué" de la institución universitaria; y, por el otro, la autonomía procedimental, concebida como la capacidad para establecer los medios mediante los cuales alcanzar objetivos, programas y metas, es decir, el "cómo" de la organización. Fines y medios 
se articulan tanto en la universidad en cuanto conjunto como en un Indesco renovado en el ambiente despejado después de la crisis de finales del siglo anterior. Medios y fines quedaron en el resorte institucional y constituyeron la base de identificación de un rasgo sustancial de la autonomía en función de su misión. Ambas autonomías están llamadas a demostrar coherencia interna y en relación con su entorno.

Lo que fue concebido como una tipología sensu stricto devino históricamente en un continuo que significaba cambio de los ejes sobre los cuales se concebía la universidad y su rol en la sociedad. A medida que se producían los cambios, la posición tradicional mostraba elementos de renovación. Uno de ellos es la concepción de universidad ubicada en la localidad y, al mismo tiempo, en la región y en la globalidad.

La universidad, por ser ella un servicio público de educación superior, asume el compromiso de incidir en la transformación de su entorno inmediato y mediato para mejorar la calidad de vida de la población. Esto significa que sus funciones sustantivas de docencia, de investigación y de proyección institucional se orientan a identificar y contribuir a la superación de necesidades, al desarrollo cultural y a la conservación y el mejoramiento del medio ambiente (Romero, 2001).

La Universidad ha mantenido su fortaleza financiera en la última década. Si se toma en cuenta el indicador de ingresos, se ubicaba, en el 2000, en el puesto 11 en el conjunto de las cooperativas del país; y en el 2011, pasó al puesto 8 . Si el parámetro son los activos, en el 2000 se encontraba en el puesto 6 y en el 2011, en el puesto 11, dentro del mismo conjunto de cooperativas (Confecoop 2000-2011). La Universidad e Indesco se mueven en un entorno en el cual funcionaban 4972 cooperativas según datos del 2004 (Castillo, 2005). Ese entorno puede ser considerado una fortaleza para afrontar las crisis generadas en el ambiente de la globalización (Cárdenas, s. f.), con la aclaración de que la universidad no es una cooperativa sino una institución auxiliar del cooperativismo.

Si la Universidad, así como Indesco, conciben las perspectivas local y global de manera conjunta, podrán diseñar un proyecto de futuro siempre y cuando revisen el entorno para descubrir en él las dinámicas que ofrece. La Universidad, junto con Indesco, conforman una sociedad que fortalece a ambos proyectos siempre y cuando logren articularse y maximizar sus recursos, así como el talento humano. La euforia de la globalización debe tomarse como una oportunidad con sus riesgos conexos. Lo que plantean Borja y Castells, según lo cual "lo global y lo local son complementarios, creadores conjuntos de sinergia social y económica" (1997, p. 14) es, para la región latinoamericana, más una posibilidad que una realidad. A la Universidad le es factible perseguir esa posibilidad a condición de asirse de la identidad que ha construido y reconstruido históricamente en el nuevo contexto local y global. Al fin y al cabo, universidad se asocia con universalidad $y$, por este camino, con globalidad.

Si el proceso de globalización actual se desarrolla sobre los rieles de los avances científicos y tecnológicos, a la Universidad no le queda otro camino que "ser universidad", es decir, centrar su proyecto futuro en su misión y vincular a ella, como un elemento esencial, a Indesco, sobre el cual desarrolla su proyección institucional. Si se quiere, en cuanto universidad produce, distribuye y consume conocimiento científico (modo 1), y en cuanto cooperativa vuelca ese conocimiento científico sobre el contexto local, regional, nacional e internacional (modo 2; Gibbons et al., 1997, 1998).

Si el Estado fomenta estructuras nacionales, las referencias para la Universidad son de ese mismo nivel; si las estructuras son subnacionales (Sassen, 1998, 2003, 2010), allí encontrará sus sedes ligadas a sus contextos regionales. La legitimidad social y política otorgada a esas entidades subnacionales como consecuencia de la descentralización y la regionalización pueden canalizarse con beneficio de inventario para los fines de la universidad. La justificación proviene de estudios en ciencias sociales sobre la globalización que indican cómo, si ella reside, en parte, en los ámbitos nacionales, es porque se atienden dos supuestos. El primero se refiere a que los Estados-nación todavía tienen un papel activo como contenedores de los procesos sociales; y el segundo es la correspondencia implícita entre el territorio nacional y lo nacional como una de sus características. En consecuencia, hay que tener en cuenta el ámbito nacional mientras tenga el reconocimiento que lo ha acompañado hasta que entre en un proceso de deslegitimación y decadencia para pasar a un Estado posnacional aún por construir (Beck, 2002a; Beck, 2004; Castells, 1999; Sassen, 2010; Wallerstein, 2001, 2004, 2005). El panorama está abierto porque la historia no se ha escrito en su totalidad y la demostración es que, como señala Wallerstein en una entrevista: "No está del lado de nadie" (Coolen, 2002). 
Las cooperativas pueden ser el camino por el cual la Universidad se abra a una perspectiva regional latinoamericana y mundial. Si esto fuera así, el camino hacia la globalidad le resulta más expedito. Organismos internacionales como la Unesco o el Banco Mundial han abierto caminos hacia la globalización del conocimiento y, desde luego, de las instituciones que los producen y los distribuyen.

El análisis sobre la globalización de los años recientes indica dos conclusiones: por un lado, esta se desarrolla a medida que el conocimiento científico y tecnológico avanza. Ahora bien, este tipo de conocimiento es la razón de ser de la universidad. Entonces, en la medida en que desarrolle esa misión, estará sobre los rieles de la globalización. Luego, fortalecer la investigación es una tarea inaplazable en el propósito de renovar los conocimientos disponibles y atender los requerimientos del entorno. Se requiere renovar los procedimientos para una adecuada canalización y articulación de los esfuerzos de los investigadores en el conjunto de la universidad, en sus 18 sedes. Cada vez menos debe ser considerada una actividad individual y centrada en cada uno de los grupos: en la medida en que existan proyectos conjuntos se maximizarán las potencialidades y se multiplicarán los beneficios.

Por otra parte, es claro que la desigualdad e inequidad serán mayores a medida que corran los años, como ha sido argumentado en numerosos estudios (Gambina, 2002; Calderón, 2009; Cepal, 2012; Di Virgilio, Otero y Bonioli, 2010; Eibenschutz, Támez y Camacho, 2008; Muiños, 1999; PNUD, 2011). El problema es que el Estado pierde el poder de contención de los efectos directos, colaterales o derivados de la acción neoliberal. Si él todavía tuviera fuerzas para intervenir, se convertiría, como lo es en la actualidad, en un obstáculo para las empresas transnacionales que preferirían un Estado "mínimo" que les facilite sus operaciones. Para la Universidad, resulta una oportunidad por cuanto la demanda por educación superior aumentará para los sectores sociales con los cuales ha decidido vincularse desde su creación. Su proyecto se puede revitalizar en función de la población que espera sus servicios. Los dos aspectos anteriores encuentran realización en las autonomías regionales y en la miniaturización del ámbito nacional focalizado en las localidades. La región latinoamericana es foco de atención de estas empresas estimuladas por quienes dirigen el Estado-nación. Si las cooperativas pueden aglutinar mano de obra preparada por la Universidad y asociada cooperativamente, se encontrará un camino para atenuar los efectos perversos de la volatilidad de las empresas y los capitales, pero solo a condición de asumir la organización en su significado solidario (Vargas, 2005).

La Universidad, en virtud de sus definiciones básicas, está comprometida con dos instancias tradicionalmente polarizadas y hoy perfectamente convergentes, como son la atención al nivel nacional y a las necesidades regionales y locales. La polarización se remonta a nuestra vida republicana y a las disputas entre posiciones centralistas y descentralistas, entre unidad nacional y poderes regionales. Poco a poco, hemos comprendido la artificialidad de estas antinomias y la necesidad de buscar elementos articuladores para atender estas dos instancias como complementarias. Todo lo anterior supone volver a la recomendación de Kaufman (2000) cuando planteaba: "Piense globalmente; actúe localmente" (citado por Vizcaíno y Muñoz, 2015). Los planes estratégicos - del nivel nacional y de las sedes de la Universidad- podrían enderezarse en esta dirección. Iguales consideraciones tienen los programas académicos que deberían incluir estas reflexiones sobre los ámbitos local y global. Los estudiantes, y los asociados a las cooperativas, han de tener presente que el capitalismo ha sido el artífice de la globalización (Ortiz, 1998), y que ella ha de recibirse con las reservas críticas que aún conserva la universidad como espacio de formación de personas abiertas, reflexivas y analíticas (Martin y Schumann, 1998; Stiglitz, 2002). Esto concuerda perfectamente con el postulado de la Universidad que valora la solidaridad, la equidad, el respeto a la diversidad y la libertad como fundamentos de la construcción de una nueva sociedad.

Las universidades son escenarios cada vez más complejos en su interior y cada vez más competitivos con respecto a otras instituciones de su género. Todas las universidades han adoptado, directa o indirectamente, una relación con la globalización. Sin embargo, hay aspectos que desarrolla la globalización que pueden convertirse en mecanismos perversos. Uno de ellos es el afán de figurar en los ránquines internacionales como el ideal de las universidades. El riesgo no está en la producción de calidad, ni en mostrar los avances de una institución; tampoco en la visibilidad nacional e internacional que ellas alcanzan. Lo perverso está en que, al consagrar tantos esfuerzos a esos objetivos se descuiden los demás frentes de acción y queden reducidos a una 
prioridad secundaria. Muchas veces la pretensión de figurar en un espacio global hace perder el sentido de realidad inmediata que es el compromiso con la región y la localidad, sobre las cuales deben rendir cuentas en virtud del carácter público de su actividad. Por otro lado, en la dinámica de las universidades, es fácil invertir los términos de lo que representan los medios y las finalidades. Los medios, como la infraestructura, las finanzas, el registro calificado o la acreditación, fácilmente pasan a ser finalidades y a ordenar lo demás a su servicio, incluso la vocación originaria y su propia identidad. Hay que rescatar la transformación cultural de la universidad con el fin de ordenarla en función de objetivos como los de crear ciudadanía con personas que vivan en paz.

Los nuevos escenarios creados en Colombia en la expectativa del fin del conflicto armado para la búsqueda de soluciones políticas resultan inéditos en el país. Las generaciones actuales tienen el compromiso con sus sucesores de crear y compartir ambientes saludables en los cuales sus potencialidades se puedan desarrollar para beneficio de la colectividad. Las cooperativas y demás organizaciones solidarias, en cumplimiento de su justificación existencial, se han adherido a propuestas en esta dirección. La Universidad Cooperativa de Colombia está llamada a unirse a ellas y a compartir espacios en los cuales el clima de la solidaridad sea posible sin discriminaciones ni exclusiones. Allí encontrará el camino expedito para los avances en la profundización de su identidad institucional. Los signos apuntan en esta dirección. La declaración está en el "Plan estratégico 2013-2022: Navegando Juntos", en el cual se reconoce a la Universidad Cooperativa de Colombia como entidad de educación superior que se compromete con la formación de "personas competentes para responder a las dinámicas del mundo, contribuimos a la construcción y difusión del conocimiento, apoyamos el desarrollo competitivo del país a través de sus organizaciones y buscamos el mejoramiento de la calidad de vida de las comunidades, influidos por la economía solidaria que nos dio origen". Los términos se clarifican si se comprende que la formación que realiza la Universidad en pregrado, posgrado y extensión "promueva las competencias para la vida colectiva ejerciendo una ciudadanía activa, contribuyendo a los procesos de calidad a través de la acreditación y la proyección social", como declara el plan estratégico.
El horizonte al cual se dirige la Universidad reconoce que "la solidaridad en este contexto es a la vez un valor social, un sentimiento moral y una postura política que se compromete con la equidad, la justicia, el buen vivir, el desarrollo y la paz. También es una forma específica de ejercer la ciudadanía y de hacer economía" (Indesco, 2013). Es fundamental el rescate de "una mirada socio-histórica visiblemente comprometida con la transformación social" que concuerda con las raíces de la identidad y contrasta la dicotomía teórica entre economía, bienestar colectivo y vínculos sociales para, de paso, cuidarse de no desnaturalizar la desigualdad y el determinismo histórico del pensamiento económico, por cuanto conoce de manera científica la realidad local y la incorporación de prácticas solidarias a los objetivos estratégicos que la inviten a vincularse con su comunidad y a buscar posibilidades de aportar al desarrollo local, imbuidos por la cultura solidaria "como su valor supremo" (Guerra, 2006, p. 5). Ese valor es el que anuda los elementos de la identidad y asegura que ellos estén direccionados hacia objetivos y metas estratégicas propias de su institucionalidad. No existe la generación espontánea como tampoco el surgimiento al azar de una cultura con los elementos expuestos; solo la intencionalidad en la acción humana colectiva puede construir un espacio con estas dimensiones. La razón está en que "la cultura solidaria reconoce en la condición humana la del sujeto político, aquel que se construye en la relación con otros en la definición de un campo común de encuentro, lo público" (Indesco, 2013). Las indispensables competencias en las dimensiones del ser, el saber y el hacer han de ser construidas en cada persona y colectividad de tal manera que su anclaje asegure permanencia y continuidad. El aprendizaje social pasa por un proceso de objetivación y subjetivación que hagan coherentes las actividades con los objetivos estratégicos que redunden en modos de vida políticamente aceptables y estratégicamente deseables para todos.

Se requiere una intensa labor de profundización en la "activación de una ciudadanía que comprometa y empodere a los individuos y las colectividades con el aporte de soluciones innovadoras y sostenibles a problemas tan complejos como la pobreza, la sostenibilidad ambiental, la inequidad y la exclusión social", en una "acción coordinada entre actores públicos, privados y las organizaciones sociales" (García, Gómez, Hernández y Pérez, 
s. f.). Todo lo anterior pasa por el reconocimiento del alto valor que contiene y puede proyectar la educación, particularmente la educación superior. En esta dirección, la Universidad concuerda con los planteamientos de la directora general de la Unesco cuando afirma:

No existe una fuerza transformadora más poderosa que la educación para promover los derechos humanos y la dignidad, erradicar la pobreza y lograr la sostenibilidad, construir un futuro mejor para todos, basado en la igualdad de derechos y la justicia social, el respeto de la diversidad cultural, la solidaridad internacional y la responsabilidad compartida, aspiraciones que constituyen aspectos fundamentales de nuestra humanidad común". (Unesco, 2015, p. 4)

Por asumir el campo de la educación con todas sus potencialidades, la Universidad Cooperativa de Colombia ha encontrado en la educación el espacio de su propia realización como institución proyectada hacia la comunidad de la cual, a su vez, desprende su identidad. Como se planteó en el epígrafe de Immanuel Wallerstein, "la historia no está al lado de nadie"; el destino institucional no está marcado a priori, continúa en construcción sobre el eje que le otorga su identidad que es la solidaridad. La apropiación del concepto de "territorio solidario para la paz" se convierte en un macroproyecto que anuda subproyectos, metas y acciones en beneficio de la comunidad en la cual desarrolla su vocación originaria. Su compromiso con ella le permite demostrar su capacidad de "navegar juntos" como "una universidad, todo un país”.

\section{Agradecimientos}

El autor agradece las sugerencias de directivos, docentes e investigadores quienes leyeron de manera crítica el documento original, en particular, a Maritza Rondón Rondón Rangel, Juan Carlos Pérez Pérez-Soto, Colombia Pérez Pérez, César Augusto Pérez Pérez y Ruth E. Muñoz Muñoz.

\section{Referencias}

Aguado, J. C. y Portal, M. A. (1991). Tiempo, espacio e identidad social. Alteridades, 1(2), 31-41.

Alter, N. (2001). Linnovation ordinaire. París: Presses Universitaires de France.

Artese, M. (2012). Oral narrative and interactional institutional identities in a university second language classroom. Macerata: University of Macerata. Recuperado de: http://www.soas.ac.uk/clp/doctoral-seminar/ file75700.pdf.

Atcon, R. P. (2005/1961). La universidad latinoamericana: clave para un enfoque conjunto del desarrollo coordinado social, económico y educativo en la América Latina. Bogotá: Universidad Nacional de Colombia.

Banco Mundial. (2007). Education quality and economic growth. Washington: The International Bank for Reconstruction and Development/The World Bank.

Barbé, C. (1984). Identidad e identidades colectivas en el análisis del cambio institucional. Revista de Estudios Políticos, 37, 67-88.

Barrie, S. C. (2004). A research-based approach to generic graduate attributes policy. Higher Education Research \& Development, 23(3), 261-275.

Barrie, S. C. (2006). Understanding what we mean by the generic attributes of graduates. Higher Education, $51,215-241$.

Bauman, Z. (2005). Identidad. Buenos Aires: Editorial Losada.

Beck, U. (1996). Teoría de la sociedad del riesgo. En J. Beriain (Comp.), Las consecuencias perversas de la modernidad (pp. 201-222). Barcelona: Anthropos.

Beck, U. (2002a). La sociedad del riesgo global. Madrid: Siglo XXI.

Beck, U. (2002b). Libertad o capitalismo: conversaciones con Johannes Willms. Barcelona: Paidós.

Beck, U. (2004). Poder y contrapoder en la era global: la nueva economía política mundial. Barcelona: Paidós.

Berger, P. y Luckmann, T. (1997). Modernidad, pluralismo y crisis de sentido. Barcelona: Paidós.

Berger, P. y Luckmann, T. (1998). La construcción social de la realidad (15a ed.). Buenos Aires: Amorrortu Editores.

Borja, J. y Castells, M. (1997). Local y global. La gestión de las ciudades en la era de la información. Barcelona: Santillana-Taurus.

Borja, M., Pineda, J. y Vizcaíno, M. (2012). Orlando Fals Borda: una vida de compromiso social. Bogotá: Escuela Superior de Administración Pública. 
Bourdieu, P. (1997). Razones prácticas: sobre la teoría de la acción. Barcelona: Editorial Anagrama.

Bourdieu, P. (2007). El sentido práctico. Buenos Aires: Siglo Xxi.

Calderón, M. (2009). Globalización neoliberal y campesinado: los efectos de la expansión capitalista en la economía campesina. Estudio de caso: Tome Alto, IV Región, Chile (Tesis de grado). Universidad Academia de Humanismo Cristiano, Chile. Recuperado de http://bibliotecadigital.academia.cl/ handle/123456789/273.

Canto, J. M. y Moral, F. (2005). El sí mismo desde la teoría de la identidad social. Escritos de Psicología, 7, 59-70.

Capdevielle, J. (2011). El concepto de habitus: "con Bourdieu y contra Bourdieu". Anduli. Revista Andaluza de Ciencias Sociales, 10, 31-45.

Cárdenas, P. E. (s. f.). El contexto socioeconómico del cooperativismo. Recuperado de http://www.codema.coop/ wordpress $/ ? \mathrm{p}=43$.

Cardoso, F. E. y Faletto, E. (1977). Dependencia y desarrollo en América Latina. México: Siglo xxi Editores.

Castells, M. (1999). La era de la información (Vol. II: El poder de la identidad). México: Siglo xxi Editores.

Castillo, D. (2005). Integración económica e intercooperación en el sector solidario colombiano. Revista Red Unircoop Américas, 1(serie 3).

Cataño, G. (1997). El Merton esencial. Revista Colombiana de Educación, 35, 115-119.

Comisión Económica para América Latina y el Caribe -Cepal. (2012). Panorama económico y social de América Latina y el Caribe. Cepal. Recuperado de http:// www.albasud.org/noticia/es/397/la-deuda-y-la-espada-neoliberalismo-en-am-rica-latina-y-el-sur-de-europa\#sthash.RDVJ7IoT.dpuf.

Consejo para la Educación Superior-CESU. (2014). Acuerdo por lo superior 2034: propuesta de política pública para la excelencia de la educación superior en Colombia en el escenario de la paz. Bogotá: CESU. Recuperado de https://www.dialogoeducacionsuperior. edu.co/1750/articles-321515_recurso_1.pdf.

Confederación de Cooperativas de Colombia. [Confecoop]. (2000-2011). Escalafón cooperativo. Confecoop.coop. Recuperado de http://www.confecoop. coop/index.php?option=com_content\&view $=$ article\&id=96: escalafon-cooperativo-incluye-2009\&catid=40:estadistica\&Itemid $=41$.

Chevallier, J. (1994). Identité, organisation, institution. En L'identité politique (pp. 239-251). Parñis: Presses universitaires de France.

Coolen, B. (2002, mayo). Entrevista a Immanuel Wallerstein. Revista Cooperación Internacional del Ministerio de Relaciones Exteriores de Holanda.
Cortés V. D. (2011). Aportes para el estudio de la identidad institucional universitaria: El caso de la UNAM. Perfiles 33, (número especial), 78-90.

Di Virgilio, M. M., Otero, M. P. y Bonioli, P. (2010). Pobreza y desigualdad en América Latina y el Caribe. Buenos Aires: Consejo Latinoamericano de Ciencias Sociales-Clacso.

Dubar, C. (1991). La socialisation. Construction des identités sociales et professionnelles. París: Armand Colin.

Dubet, F. (1989). De la sociología de la identidad a la sociología del sujeto. Revista de Estudios Sociológicos, 7(21), 519-545.

Eibenschutz, C., Támez, S. y Camacho, I. (2008). Desigualdad y políticas sociales erróneas producen inequidad en México. Revista Salud Pública, 10(1), 119-132.

Eurydice: red europea de información en educación. (2002). Las competencias clave: un concepto en expansión de la educación general obligatoria. Madrid: Eurydice.

Ferrante, C. (2008). Corporalidad y temporalidad: fundamentos de la teoría práctica de Pierre Bourdieu. Nómadas, Revista Crítica de ciencias Sociales y jurídicas, 20(4), 1-25.

Ferrante, C. (2010). El debate objetivismo-subjetivismo en la teoría de la práctica. Intersticios. Revista sociológica de pensamiento crítico, 4(1), 79-93.

Fleury, S. (2003). La expansión de la ciudadanía. Inclusión social y nuevas ciudadanías. Bogotá: Editorial Pontificia Universidad Javeriana.

Furtado, C. (1974). El desarrollo económico: un mito. México: Siglo xxI.

Gambina, J. (Comp.). (2002). La globalización económico-financiera su impacto en América Latina. Buenos Aires: Clacso.

García, A. (1969). La estructura del atraso en América Latina. Buenos Aires: Ed. Pleamar.

García, A. (1972). Atraso y desarrollo en América Latina. Elementos para una teoría latinoamericana del desarrollo. Buenos Aires: El Ateneo.

García, A. (1979). Ensayos sobre el proceso histórico latinoamericano. México: Editorial Nuestro Tiempo.

García-Canclini, N. (1982). Las culturas populares en el capitalismo. México: Nueva Imagen.

García, S., Gómez, M. E., Hernández, I. y Pérez, C. (s. f.). Educación superior y economía social y solidaria: aportes a la construcción de territorios solidarios para la paz. Bogotá: Universidad Cooperativa de Colombia.

Gibbons, M. (1998, octubre). Pertinencia de la educación superior en el siglo xxi. En Conferencia Mundial sobre la Educación Superior, realizada en París, del 5 al 
9 de octubre de 1998. Unesco. Recuperado de http:// www.humanas.unal.edu.co/contextoedu/docs_sesiones/gibbons_victor_manuel.pdf.

Gibbons, M., Limoges, C., Nowotny, H., Schwartzman, S., Scott, P. y Trow, M. (1997). La nueva producción del conocimiento: la dinámica de la ciencia y la investigación en las sociedades contemporáneas. Barcelona: Ediciones Pomares.

Giddens, A. (1995). La constitución de la sociedad: bases para la teoría de la estructuración. Buenos Aires: Amorrortu.

Giddens, A. (1996). Modernidad y autoidentidad. En J. Beriain (Comp.), Las consecuencias perversas de la modernidad: modernidad, contingencia y riesgo (pp. 33-71). Barcelona: Anthropos.

Gilbert, R., Balatti, J., Turner, P. y Whitehouse, H. (2007). The generic skills debate in research higher degrees. Higher Education Research \& Development, 23(3), 375-388. doi: https://doi.org/10.1080/07294360420 00235454 .

Gomes Da Silva, J. R. (2010). La dynamique identitaire entre organisations et individus. Le cas de cinq organisations brésiliennes. Revue française de gestion, 36(203), 185204. doi: https://doi.org/10.3166/rfg.203.185-204.

Guerra, P. (2006, mayo). La economía de la solidaridad o la vuelta de los valores sociales a la economía. Revista Umbrales, 168, 1-7.

Gutiérrez, G. R. (2004). Modernismo: supuestos históricos $y$ culturales ( $3^{\mathrm{a}}$ ed.). México: Fondo de Cultura Económica.

Hambur, S., Rowe, K y Le, T. L. (2002). Graduate Skill Assessment: Stage One Validity Study. Canberra, ACT: The Australian Council for Educational Research (Ed.), Commonwealth Department of Education, Science and Training.

Hunt, M. M. (1996). ¿Por qué suceden las cosas así? Un perfil de Robert K. Merton. Revista Colombiana de Educación, 33, 127-146.

Larraín, J. (2005). ¿América Latina moderna? Globalización e identidad. Santiago de Chile: LOM Ediciones.

Maldonado, A. M. y Hernández, A. V. (2010). El proceso de construcción de la identidad colectiva. Convergencia, 17(53), 229-251.

Mannheim, K. (1957). Ensayos de sociología de la cultura. Madrid: Editorial Aguilar.

Mannheim, K. (1969). El hombre y la sociedad en la época de crisis. Buenos Aires: Editorial Manantial.

Marshall, Th. H. (1997). Ciudadanía y sociedad. Revista de Estudios e Investigaciones Sociales-REIS, 79, $297-$ 344.

Martín, H. P. y Schumann, H. (1998). La trampa de la globalización: el ataque contra la democracia y el bienestar. Madrid: Taurus y Santillana.
Merton, R. K. (1977). La sociología de la ciencia. Madrid: Alianza Editorial.

Merton, R. K. (1980). Teoría y estructura sociales (2a ed.). México: Fondo de Cultura Económica.

Mills, C. W. (1961). La artesanía intelectual. En La imaginación sociológica (pp. 206-236). México: Fondo de Cultura Económica.

Ministerio de Educación Nacional. (2011). Propuesta de lineamientos para la formación por competencias en educación superior. Recuperado de www.mineducacion.gov.co/1621/articles-261332_archivo_pdf_lineamientos.pdf.

Mollis, M. (2003). Un breve diagnóstico de las universidades argentinas: identidades alteradas. En Las universidades en América Latina: ¿reformadas o alteradas? La cosmética del poder financiero (pp. 203-216). Buenos Aires: Editorial Clacso.

Mollis, M. (2008, julio). Las reformas de la educación superior en Argentina para el nuevo milenio. Avaliação, Campinas; Sorocaba, SP, 13(2), 509-532.

Mollis, M. (2010). Las transformaciones de la educación superior en América Latina: ¿identidades en construcción? Educación superior y sociedad-ESS, 15(1), 11-23.

Mollis, M. (2012). Las máscaras del saber en las universidades latinoamericanas. En Cátedra Manuel Ancízar 2012-I. Educación superior: debates y desafíos, marzo de 2012 (Manuscrito inédito). Universidad Nacional de Colombia, Bogotá.

Muiños, J. B. (1999). Neoliberalismo y desigualdad social en Europa y América. Scripta Nova, Revista Electrónica de Geografía y Ciencias Sociales, 45(9). Recuperado de http://www.ub.edu/geocrit/sn-45-9.htm.

Ocampo, J. F. (1981). Reforma universitaria 1960-1980. Bogotá: Cinep.

Organización para la Cooperación y el Desarrollo Económicos-OECD. (2007). Assessing higher education learning outcomes summary of a first meeting of experts. Recuperado de http://www.oecd.org/education/skills-beyond-school/39117243.pdf.

Organización para la Cooperación y el Desarrollo Económicos-OECD. (2009). Roadmap for the OECD assessment of higher education learning outcomes (AHELO) feasibility study. Recuperado de http://www.oecd. org/education/skills-beyond-school/41061421.pdf.

Ortiz, R. (1998). Otro territorio: ensayos sobre el mundo contemporáneo. Bogotá: Convenio Andrés Bello.

Pacheco, T. (2005). Universidad, sociedad y modernidad en el contexto de las ciencias sociales. México: Fontamara.

Perenoud, Ph. (2008). Construir las competencias, ¿es darle la espalda a los saberes? REDU, Revista de Docencia Universitaria, 6(2), 1-16. doi: https://doi. org/10.4995/redu.2008.6270. 
Pérez, M. C. y Rúa, S. (2013). Lineamientos educativos para la formación en economía solidaria. Bogotá: Indesco.

Programa de Naciones Unidas para el Desarrollo-PNUD. (2011). Informe sobre Desarrollo Humano 2011. PNUD. Recuperado de http://www.albasud.org/noticia/es/397/ la-deuda-y-la-espada-neoliberalismo-en-am-rica-latina-y-el-sur-de-europa\#sthash.RDVJ7IoT.dpuf

Tuning Project. (2005). Tuning Educational Structures in Europe II: Universities' contribution to the Bologna process. Bilbao: Tuning Project. Recuperado dehttp:// tuningacademy.org/wp-content/uploads/2014/02/ TuningEUII_Final-Report_EN.pdf.

Rojas, H. y Camacho, Á. (1973). Frente Nacional: ideología y realidad. Bogotá: Punta de Lanza.

Romero, A. (2001, enero-abril). Universidad y globalización. Revista de Ciencias Sociales (RCS), 7, 141-151.

Sassen, S. (1998, marzo). Ciudades en la economía global: enfoques teóricos y metodológicos. Revista Eure, 24(71), 5-25.

Sassen, S. (2003, diciembre). Localizando ciudades en circuitos globales. Revista Eure, 29(88), 5-27.

Sassen, S. (2010). Una sociología de la globalización. Buenos Aires: Katz.

Schütz, A. (1964a). El ciudadano bien informado. Ensayo sobre la distribución social del conocimiento. En A. Schütz (Ed.), Estudios sobre teoría social (pp.120132). Buenos Aires: Amorrortu.

Schütz, A. (1964b). Tiresias, o nuestro conocimiento de sucesos futuros. En A. Schütz (Ed.), Estudios sobre teoría social (pp. 255-269). Buenos Aires: Amorrortu.

Serrano, R. (2007). La democracia en las cooperativas. Revista Cooperativismo \& Desarrollo, 91, 64-79.

Smith, A. (1997). Identidad nacional. Madrid: Editorial Trama.

Solís, M. (2004, mayo-diciembre). Reflexiones en torno a la producción de sentido en el mundo moderno: una lectura de modernidad, pluralismo y crisis de sentido de Peter Berger y Thomas Luckmann. Revista Filosofía Universidad Costa Rica, 42(106-107), p. $75-82$.

Stiglitz, J. E. (2002). El malestar de la globalización. Bogotá: Taurus y Santillana.

Sunkel, O. (1970). Conceptos de subdesarrollo y desarrollo. El subdesarrollo latinoamericano y la teoría del desarrollo. México: Siglo xxi.
Sveningsson, S. y Alvesson, M. (2003). Managing managerial identities: Organizational fragmentation, discourse and identity struggle. Human Relations, 56(10), 1163-1193. doi: https://doi.org/10.1177/00187267035610001.

Universidad Cooperativa de Colombia-ucc. (1971). Conclusiones de Santandercito (corregimiento del municipio de San Antonio del Tequendama en el departamento de Cundinamarca). Mimeo.

Universidad Cooperativa de Colombia-ucc. (2005, julio). Balance social 2003-2004. Bogotá: Universidad Cooperativa de Colombia.

Universidad Cooperativa de Colombia-Ucc. (2009). Guía institucional. Ucc.edu.co. Recuperado de http://wb.ucc. edu.co/institucional1/files/2009/05/guia-institucional-i.pdf

Universidad Cooperativa de Colombia-UCc. (2012). Misión. Ucc.edu.co. Recuperado de http://www.ucc. edu.co/institucion/Paginas/mision-vision.aspx

Uribe, C. (1978). El cooperativismo ayer y hoy. Armenia Colombia: Banco de la República y Quingráficas.

Uribe, C. (2005, julio). El discurrir histórico de la Universidad Cooperativa de Colombia. En Balance Social 2003-2004 (pp. 12-19). Bogotá: Universidad Cooperativa de Colombia

Vargas, M. C. (2005). Globalización, desarrollo regional y atomización del Estado nación (Tesis de maestría). Universidad de los Andes, Bogotá, Colombia.

Villamizar, J. C. (2013). La influencia de la Cepal en Colombia, 1948-1970. Bogotá: Universidad del Rosario.

Vizcaíno, M. y Amaya, J. (2006). Universidad: exclusión y desigualdad. Bogotá: Editorial Universidad Cooperativa de Colombia.

Vizcaíno, M. y Muñoz, R. E. (2015). La institucionalización de la investigación en Colombia: revisión histórica de una universidad nacional y regional. Bogotá: Ediciones Universidad Cooperativa de Colombia.

Wallerstein, I. (2001). Conocer el mundo, saber el mundo. El fin de lo aprendido: una ciencia social para el siglo XXI. México: Siglo XXI.

Wallerstein, I. (2004). Capitalismo histórico y movimientos antisistémicos: un análisis de sistemas mundo. Madrid: Akal.

Wallerstein, I. (2005). Las incertidumbres del saber. Barcelona: Gedisa.

Zabludovsky K., G. (2007). Sociología y cambio conceptual. México: Siglo xxi y Universidad Autónoma Metropolitana Azcapotzalco. 